\title{
Spectrum of AIDS-defining Opportunistic Infections among Anti-retroviral treatment-naïve HIV-seropositive Cases in Northeast India
}

Sir,

The prevalence of human immunodeficiency virus (HIV) infection in Indian adults is $0.22 \%$, while it is $0.8 \%$ worldwide. ${ }^{1}$ Anti-retroviral treatment-naïve HIV patients are prone to opportunistic infections (OIs) owing to waning of their cellular immunity as their CD4+ T cell counts gradually decline. Although combined anti-retroviral treatment (cART) has reduced the prevalence of OIs in patients living with HIV, approximately one-quarter of treatment-naïve HIV patients still present with full-blown acquired immunodeficiency syndrome (AIDS). The incubation period of AIDS is 7 to 10 years. ${ }^{2}$ The aim of this study was to describe the burden and spectrum of OIs among treatment-naïve HIV patients.

\section{METHODOLOGY}

This was a prospective cohort study performed at the ART center, Khagaria, in the north-east region of

India from May' 2019 to February' 2020. All the treatmentnaïve HIV patients $\geq 6$ years of age were included in the study while 'transferred in' HIV patients were not included.

OIs were diagnosed on history-taking, clinical features, imaging features, and fluorescence microscopy of sputum smears.

HIV patients were screened for tuberculosis $(\mathrm{Tb})$ using an algorithm. ${ }^{3}$ Cases of extra-pulmonary $\mathrm{Tb}$ were diagnosed by fine needle aspiration cytology of enlarged lymph nodes $(>1 \mathrm{~cm})$, exudative pleural effusion/ascites, and ultrasonography of the abdomen for presence of Koch's abdomen. Pulmonary $\mathrm{Tb}$ along with rifampicin sensitivity and cryptococcal infections were confirmed by the Nucleic Acid Amplification Test (NAAT) and cryptococcal antigen assays, respectively.
Access this article online

Website:

http://nepjol.info/index.php/AJMS DOI: 10.3126/ajms.v12i5.33994

E-ISSN: 2091-0576

P-ISSN: $2467-9100$

Copyright (c) 2021 Asian Journal of Medical Sciences

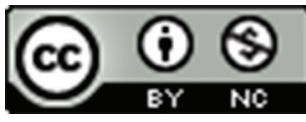

This work is licensed under a Creative Commons Attribution-NonCommercial 4.0 International License.
Oral candidiasis was diagnosed clinically and confirmed by sputum smear microscopy.

Patients with a fever and splenomegaly were screened for visceral leishmaniasis with immunochromatic RK-39 strips; the diagnosis was confirmed by demonstration of Leishman Donovan bodies (LD bodies) in bone marrow/ splenic aspirates.

Patients with a fever, cough, dyspnoea, a combative lesion in chest $\mathrm{x}$-rays and CD4+ T cell count $<200 / /$ $\mu \mathrm{l}$ were likely cases of pneumocystis jirovecii pneumonia (PJP).

Diagnosis of HIV wasting disease was made in a patient with a $10 \%$ loss of weight precipitated by diarrhea, fever and weakness $>30$ days, with the exclusion of OIs.

\section{RESULTS}

ART-naïve HIV patients ( $\mathrm{n}=257)$ were categorized as HIV mono-infection, HIV/Tb co infections, and HIV/OIs 
Table 1. showing prevalence, age, and CD4+ T cell count of treatment naïve HIV patients

\begin{tabular}{lcccc}
\hline Group n-no of patient & Prevalence (\%) & Male: Female & Age (years) mean (SD) & CD4 (cell/ $\boldsymbol{\mu l})$ mean (SD) \\
\hline HIV (n-205) & 79.7 & $1.2: 1$ & $35.2(18.3)$ & $403(258)$ \\
HIV/Tb(n-43) (MDR-Tb-3/43) & 16.7 & $2.6: 1$ & $41.3(13.1)$ & $238(159)$ \\
HIV/Ols other than Tb.(n-9) & 3.5 & $1: 2$ & $40(14.2)$ & $189(114)$ \\
\hline
\end{tabular}

other than tuberculosis; their prevalence (\%), age, and CD4+ T-cell counts are shown (Table 1).

The mean CD4+ T cell count of the HIV/Tb co-infection was well above 200 cells / $\mu$ l while, in HIV/OIs other than $\mathrm{Tb}$, it was below the 200 cells $/ / \mu$ l and when compared with HIV mono-infection they were significant at $t=4.2$ with $\mathrm{p}<0.1$ and $\mathrm{t}=2.4$ with $\mathrm{p}>0.5$ respectively.

The prevalence of OIs was observed in $20.2 \%$, while it is $22.4 \%$ in Nigeria and $9 \%$ in the USA and Canada. ${ }^{4,5}$ Multidrug resistant $\mathrm{Tb}(\mathrm{MDR}-\mathrm{Tb})$ was observed in 7\% (3/43) of $\mathrm{HIV} / \mathrm{Tb}$ co-infection patients. In fact, half of the global burden of MDR-Tb falls on India, China, and the Russian Federation. ${ }^{6}$ PJP, oral and esophageal candidiasis, and visceral leishmaniasis were only observed in two patients each, while HIV wasting disease, toxoplasmosis, and HPV infection causing cervical carcinoma were only present in one patient each; nonetheless, their presence is significant.

\section{CONCLUSIONS}

The spectrum of OIs is not uniform worldwide. PJP, Kaposi sarcoma, esophageal candidiasis, Cytomegalovirus related diseases and Mycobacterial avium complex are seen in developed countries while candidiasis, Tb, and dermatitis are highly prevalent in Nigeria.

\section{Availability of data}

Raw data; Protocol Registration available on Clinical Trials. gov; ID: NCT03993093.
Key words: AIDS; CD4 + T cell; HIV, Opportunistic infections; Multi-drug resistant Tuberculosis

Ranjan Kumar Singh

Consultant Physician, Anti-retroviral therapy Centre, District Hospital Khagaria, Bihar, India.

Address for Correspondence: Dr Ranjan Kumar Singh, Consultant Physician, Anti-retroviral therapy Centre, District Hospital Khagaria, Bihar, India.

Mobile: +91-7903488900.

E-mail: dr_ranjankumarsingh@yahoo.com

\section{REFERENCES}

1. Summary of the global HIV epidemic (2018): available from www.who.int/gho/hiv/en (assessed on 02 March 2020)

2. Bacchetti $P$ and Moss AR. Incubation period of AIDS in San Francisco. Nature. 1989; 338:251-253.

https://doi.org/10.1038/338251a0

3. Cain KP, McCarthy KD, Heilig CM, Monkongdee P, Tasaneeyapan T, Kanara N, et al. An algorithm for tuberculosis screening and diagnosis in people with HIV. N Engl J Med. 2010; 362:707-716.

https://doi.org/10.1056/NEJMoa0907488

4. Iroezindu MO, Ofondu EO, Hausler $\mathrm{H}$ and Wyk BV. Prevalence and risk factors for opportunistic infections in HIV patients receiving antiretroviral therapy in a resource-limited setting in Nigeria. J of AIDS and Clinic Res. 2013; S3.

https://doi.org/10.4172/2155-6113.S3-002

5. Buchacz K, Lau B, Jing Y, Bosch R, Abraham AG, Gil MJ, et al. AIDS Defining Opportunistic Infections in a Multicohort Analysis of HIV-infected Persons in the United States and Canada, 20002010. J Infect Dis. 2016; 214:862-872.

https://doi.org/10.1093/infdis/jiw085

6. Facts sheet/ tuberculosis: available from www.who.int/news-room/ fact-sheets/detail/tubercuosis. (accessed on 30 March 2020)

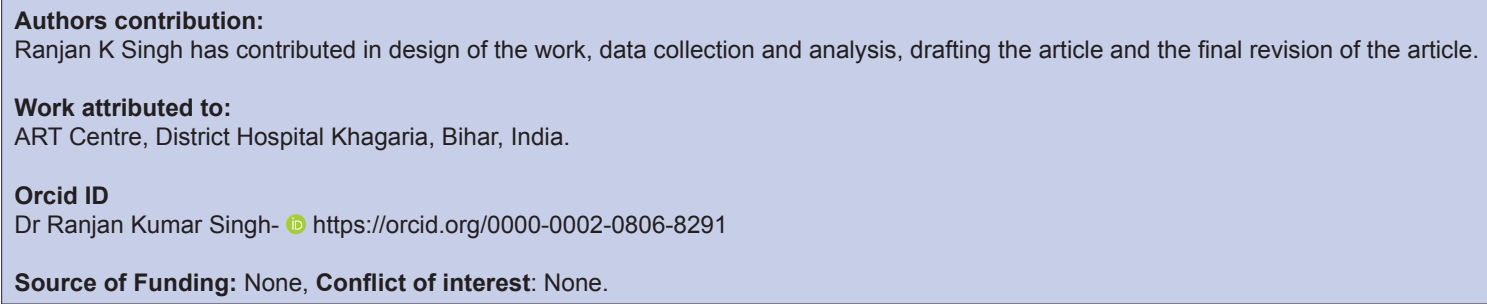

